\title{
Necessidades hídricas de bananeira tipo Terra em condições de tabuleiros costeiros
}

\author{
Eugênio Ferreira Coelho(1), Raone Cotrim de Oliveira( ${ }^{(2)}$ e Arthur José Mendes Pamponet( ${ }^{(2)}$
}

\begin{abstract}
(1)Embrapa Mandioca e Fruticultura, Cruz das Almas, Rua Embrapa, s/no, Caixa Postal 007, CEP 44380-000 Cruz das Almas, BA. E-mail: eugenio.coelho@embrapa.br (2)Universidade Federal do Recôncavo da Bahia, Campus Cruz das Almas, Caixa Postal 007, CEP 44380-000 Cruz das Almas, BA. E-mail: raonecotrim@yahoo.com.br, arthurpamponet@gmail.com
\end{abstract}

Resumo - O objetivo deste trabalho foi avaliar os efeitos de diferentes lâminas de água nas variáveis morfofisiológicas e de produção de três cultivares de bananeira do tipo Terra. Utilizou-se o delineamento experimental de blocos ao acaso, em arranjo fatorial com 12 tratamentos e três repetições. Os tratamentos consistiram de lâminas de água correspondentes a 33, 66, 99 e 120\% da evapotranspiração da cultura (ETc), além do controle sem irrigação, e das cultivares Terra Maranhão, Terrinha e D'Angola. Avaliaram-se as variáveis morfofisiológicas: altura de planta, diâmetro do pseudocaule, área foliar, condutância estomática e, na colheita, número de dedos e de pencas, e peso de pencas por cacho. Os coeficientes de cultura das cultivares de bananeira tipo Terra foram obtidos a partir da melhor combinação de produtividade e eficiência de uso de água. As lâminas de água de uso consuntivo de $1.599 \mathrm{~mm}$ (1,20 da ETc), $922 \mathrm{~mm}(0,84 \mathrm{da} \mathrm{ETc})$ e $940 \mathrm{~mm}(1,06$ da ETc) correspondem às máximas produtividades e eficiências de uso de água das cultivares Terra Maranhão, Terrinha e D'Angola, respectivamente.

Termos para indexação: Musa, banana tipo Terra, coeficiente de cultura, condutância estomática, plátano, produção.

\section{Water requirements of Terra-type banana under coastal tableland conditions}

\begin{abstract}
The objective of this work was to evaluate the effects of different water depths on the morphophysiological and yield variables of three Terra-type banana cultivars. A randomized complete block design was used, in a factorial arrangement with 12 treatments and three replicates. Treatments consisted of water depths correspondent to $33,66,99$, and $120 \%$ of crop evapotranspiration (ETc), besides the control without irrigation, and of the cultivars Terra Maranhão, Terrinha, and D'Angola. The morphophysiological variables evaluated were: plant height, pseudostem diameter, leaf area, stomatal conductance, and, during harvest, the number of fingers and hands, and hand weight per bunch. Crop coefficients of the Terra-type banana cultivars were obtained from the best combination of yield and water use efficiency. The consumptive water-use depths of $1,599 \mathrm{~mm}(1.20 \mathrm{ETc}), 922 \mathrm{~mm}(0.84 \mathrm{ETc})$, and $940 \mathrm{~mm}(1.06 \mathrm{ETc})$ correspond to the maximum yields and water use efficiencies of the cultivars Terra Maranhão, Terrinha, and D'Angola, respectively.
\end{abstract}

Index terms: Musa, Terra-type banana, crop coefficient, stomatal conductance, plantain, yield.

\section{Introdução}

O plátano é uma planta herbácea pertencente à família das Musáceas, que apresentam frutos grandes, com quinas proeminentes e alto teor de amido. Os plátanos $\mathrm{AAB}$ são produzidos, em sua maioria, na África, na América Latina e no Caribe (Soto, 2011).

No Brasil, as regiões Nordeste e Norte concentram os maiores plantios de plátanos. Nas regiões Centro Oeste e Sudeste, essa bananeira tem ganhado espaço em área plantada. Esse tipo de banana faz parte do hábito alimentar das populações nortistas e nordestinas e é comercializado com preços superiores aos praticados para as bananas do subgrupo Prata; contudo, não há conhecimento de dados sobre quantidades produzidas, cultivares utilizadas e rendimento obtido (Borges et al., 2002).

De acordo com Arantes et al. (2010), são raros os trabalhos de qualquer natureza que avaliam cultivares de bananeira tipo Terra, o que se justifica pela escassez de genótipos disponíveis.

Os plátanos necessitam de $150 \mathrm{~mm}$ por mês de precipitação ou $1.500 \mathrm{~m}^{3} \mathrm{ha}^{-1}$ por mês para atender o requerimento hídrico da cultura (Cayón, 2004), porém 
não foram encontrados outros trabalhos que apoiem esta afirmação. Diversos autores têm analisado as relações hídricas da bananeira do grupo Prata (Coelho et al., 2006; Figueiredo et al., 2006; Braga Filho et al., 2008; Costa et al., 2012); porém, há poucos estudos sobre cultivares de plátanos sob irrigação (Goenaga et al., 1995; Faria et al., 2010), e a maioria não avalia o efeito de diferentes lâminas de irrigação no crescimento ou na produção da cultura. $\mathrm{O}$ crescimento de áreas plantadas com essa bananeira, associado às constantes incertezas climáticas ou à distribuição irregular de chuvas, tem aumentado o número de usuários da irrigação, o que demanda conhecimento das reais necessidades hídricas da cultura.

O objetivo deste trabalho foi avaliar os efeitos de diferentes lâminas de água nas variáveis morfofisiológicas e de produção de três cultivares de bananeira do tipo Terra.

\section{Material e Métodos}

O experimento foi instalado em área experimental da Embrapa Mandioca e Fruticultura, no Município de Cruz das Almas, na região dos tabuleiros costeiros do recôncavo baiano $\left(12^{\circ} 66^{\prime} \mathrm{S}, 39^{\circ} 15^{\prime} \mathrm{W}\right.$, a $225 \mathrm{~m}$ de altitude). No período experimental, entre janeiro de 2011 e abril de 2012, a umidade relativa média mensal foi de $78 \%$, a temperatura média mensal foi de $24^{\circ} \mathrm{C}$ e a precipitação foi de $1.223 \mathrm{~mm}$. O solo da região é classificado como Latossolo Amarelo de textura média (Souza \& Souza, 2001), cujas propriedades físicas e físico-hídricas estão apresentadas na Tabela 1.

As cultivares Terra Maranhão, Terrinha e D'Angola (AAB) foram plantadas no espaçamento de $2,5 \times 2,0 \mathrm{~m}$, com adubação e tratos culturais segundo Faria et al. (2010). O sistema de irrigação adotado foi o de microaspersão, com uma linha lateral correspondente a duas fileiras de plantas e um microaspersor de $53 \mathrm{~L}$ por hora para cada quatro plantas. Durante os eventos de irrigação, a pressão de serviço dos microaspersores foi mantida em $160 \mathrm{kPa}$, com raio médio de ação de 2,4 m e intensidade de aplicação entre 1,7 e 2,0 mm por hora.

Utilizou-se o delineamento experimental de blocos ao acaso, em arranjo fatorial $4 \times 3$ (quatro lâminas de água e três cultivares), com três repetições, o que totalizou 12 tratamentos e 36 parcelas. Cada parcela foi constituída por dez plantas, com seis plantas úteis e quatro utilizadas como bordadura (duas em cada extremidade da parcela). O fator nível de irrigação consistiu de quatro lâminas de água correspondentes a $33,66,99$ e $120 \%$ da evapotranspiração da cultura (ETc), considerada como a evapotranspiração da bananeira 'Prata Anã', estimada a partir da evapotranspiração de referência (ETo) determinada pela equação de Penman-Monteith modificada e pelos coeficientes de cultura conforme Coelho et al. (2012). O fator cultivar consistiu das cultivares Terra Maranhão, Terrinha e D'Angola. A diferenciação dos tratamentos foi feita nas linhas de derivação, uma para cada lâmina de água, controlada por registros.

O manejo da irrigação foi realizado com um intervalo fixo entre irrigações de dois dias, por reflectometria no domínio do tempo, com leituras de umidade a $0,20 \mathrm{~m}$ do pseudocaule, a $0,25 \mathrm{~m}$ de profundidade, para avaliar a necessidade ou não de irrigação, com base nos dados de retenção de água do solo (Tabela 1). A aplicação de água correspondeu à reposição da ETc ocorrida desde a última irrigação (Coelho et al., 2012).

Foram coletados, por ocasião da floração, dados de altura de planta, diâmetro do pseudocaule a $0,20 \mathrm{~m}$ do solo e área foliar. A área foliar foi obtida a partir dos valores de comprimento e largura da terceira folha, relacionados ao número total de folhas e aplicados na equação proposta por Zucoloto et al. (2008): AFT $=0,5187(\mathrm{C} \times \mathrm{L} \times \mathrm{N})+9603,5$, em que AFT é a área foliar total $\left(\mathrm{cm}^{2}\right)$; C é o comprimento da terceira folha $(\mathrm{cm})$; L é a largura da terceira folha $(\mathrm{cm})$; e N é o número de folhas.

Também foi avaliado o parâmetro fisiológico condutância estomática com porômetro portátil,

Tabela 1. Propriedades físicas e físico-hídricas do solo da área experimental.

\begin{tabular}{|c|c|c|c|c|c|c|c|}
\hline \multirow{2}{*}{$\begin{array}{l}\text { Profundidade } \\
(\mathrm{cm})\end{array}$} & \multirow[t]{2}{*}{ Areia total } & \multirow[t]{2}{*}{ Silte } & \multirow[t]{2}{*}{ Argila } & \multirow[t]{2}{*}{$\rho s$} & \multicolumn{3}{|c|}{ Umidade $\left(\mathrm{m}^{3} \mathrm{~m}^{-3}\right)$ retida a tensão $(\mathrm{kPa})$} \\
\hline & & & & & 10 & 33 & 1.500 \\
\hline $0-20$ & 732 & 87 & 181 & 1,67 & 0,1785 & 0,1761 & 0,0980 \\
\hline $20-40$ & 629 & 68 & 303 & 1,66 & 0,1964 & 0,1936 & 0,1514 \\
\hline $40-70$ & 600 & 77 & 323 & 1,43 & 0,1896 & 0,1837 & 0,1320 \\
\hline
\end{tabular}


modelo AP4 (Delta-T Devices Ltd., Cambridge, Reino Unido), previamente calibrado. Foram feitas duas observações (primeira e segunda avaliações), uma em cada semana, no período em que os eventos de irrigações foram mais frequentes na região, com a cultura na fase de crescimento de frutos. As leituras da condutância estomática foram realizadas no período da manhã (das 10:30 às 11:30 h), no limbo da terceira folha a partir da vela, antes da irrigação, ocasião em que as variáveis meteorológicas temperatura, umidade relativa do ar, radiação global e deficit de pressão de vapor na primeira e na segunda avaliação foram, respectivamente, 25,05 e $30,0^{\circ} \mathrm{C}, 75$ e $50 \%, 1,73$ e $2,17 \mathrm{MJ} \mathrm{m}^{-2}$ por hora, e 1,73 e $1,89 \mathrm{kPa}$.

As variáveis de produção analisadas por ocasião da colheita foram: número de dias do plantio até a colheita, número de pencas, número de dedos (frutos) e produtividade de pencas, diâmetro e comprimento do fruto mediano da segunda penca.

Os resultados foram submetidos à análise de variância para verificação dos efeitos das fontes de variação. As cultivares foram comparadas pelo teste de Tukey, e os efeitos das lâminas de irrigação foram avaliados pela análise de regressão, uma vez que se tratou de variáveis quantitativas. As análises estatísticas foram realizadas com uso do programa Sisvar (Ufla, Lavras, MG).

Os resultados de produtividade e eficiência de uso de água foram utilizados para definir os coeficientes de cultura (kc) das três cultivares de bananeira tipo Terra avaliadas. A eficiência de uso de água foi determinada pela razão entre a produtividade $\left(\mathrm{kg} \mathrm{ha}^{-1}\right)$ e a lâmina de água de uso consuntivo aplicada $(\mathrm{mm})$. O coeficiente de cultura foi definido para cada cultivar, pela combinação mais adequada de produtividade e eficiência de uso de água, ou seja, a melhor combinação correspondeu a uma dada fração (fr) da ETc de 'Prata Anã': $\mathrm{ETc}=\mathrm{ETo} \times \mathrm{kc}_{\mathrm{pa}}$, em que $\mathrm{kc}_{\mathrm{pa}}$ é o coeficiente de cultura de 'Prata Anã'. Assim, fr $\times$ ETc $=$ fr $\times$ ETo $\times \mathrm{kc}_{\mathrm{pa}}$; fr $\times \mathrm{kc}_{\mathrm{pa}}=\mathrm{kc}$, em que kc é o coeficiente de cultura da cultivar de bananeira tipo Terra.

\section{Resultados e Discussão}

Os valores das lâminas de água efetivamente aplicadas nos tratamentos 33, 66, 99 e 120\% da ETc, durante o período de janeiro de 2011 a abril de 2012, foram de 155, 326,8, 498,9 e 676,2 mm, respectivamente. A irrigação se iniciou no sétimo mês, quando a bananeira estava no final da fase vegetativa (Figura 1), e foi aplicada em caráter complementar ou suplementar conforme a precipitação mensal.

O fator cultivar mostrou efeito em todas as variáveis de crescimento analisadas (Tabela 2), o que era esperado pela própria estrutura morfológica de cada cultivar. Foram observados órgãos de maiores dimensões em 'Terra Maranhão', seguida por 'Terrinha' e 'D'Angola'.

Os valores médios de altura da planta variaram de 3,26 a 4,27 m, com maior média para 'Terra Maranhão' e sem diferença significativa entre 'Terrinha' e 'D’Angola'. Resultado semelhante foi obtido por Faria et al. (2010) em Guanambi, BA, região semiárida, com variação de altura média de 3,16 a $4,91 \mathrm{~m}$, nas três cultivares, o que indica maior sensibilidade da cultivar Terra Maranhão às variações de luminosidade e temperatura, distintas entre as duas regiões. A cultivar Terra Maranhão também apresentou maior diâmetro

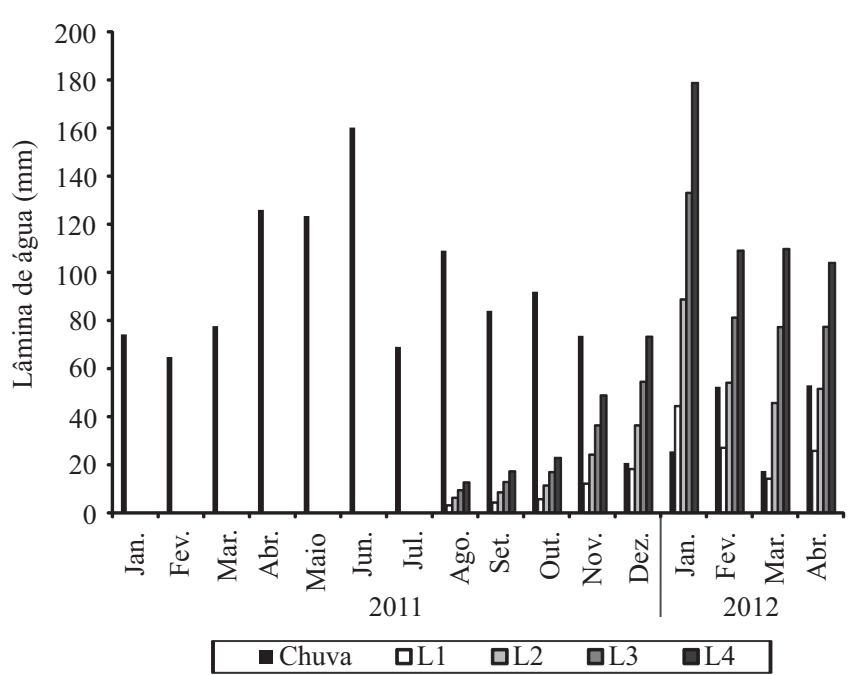

Figura 1. Lâminas de água de chuva e irrigação durante o ciclo da bananeira, de janeiro de 2011 a abril de 2012.

Tabela 2. Médias de altura da planta, diâmetro do caule e área foliar coletadas mensalmente, do pegamento das mudas à floração, e número de dias do plantio à floração (DPF) das três cultivares avaliadas em relação à média das quatro lâminas de água aplicadas ${ }^{(1)}$.

\begin{tabular}{lcccc}
\hline Cultivares & Altura $(\mathrm{m})$ & Diâmetro $(\mathrm{m})$ & Área foliar $\left(\mathrm{m}^{2}\right)$ & DPF \\
\hline D’Angola & $3,35 \mathrm{~b}$ & $0,23 \mathrm{~b}$ & $9,82 \mathrm{~b}$ & $295 \mathrm{c}$ \\
Terrinha & $3,26 \mathrm{~b}$ & $0,22 \mathrm{~b}$ & $8,95 \mathrm{~b}$ & $321 \mathrm{~b}$ \\
Terra Maranhão & $4,27 \mathrm{a}$ & $0,31 \mathrm{a}$ & $13,80 \mathrm{a}$ & $378 \mathrm{a}$ \\
\hline${ }^{(1)}$ Médias seguidas de letras iguais, minúsculas nas colunas, não diferem
\end{tabular}

pelo teste de Tukey, a 5\% de probabilidade. 
médio $(0,31 \mathrm{~m})$, tendo diferido significativamente de 'Terrinha' e 'D'Angola', que apresentaram diâmetros de 0,22 e 0,23 m, respectivamente. Da mesma forma, 'Terra Maranhão' apresentou maior valor médio para área foliar, que contrastou com os valores obtidos para as cultivares Terrinha e D'Angola, que não diferiram entre si. Isso pode ser explicado pelos diferentes portes e estrutura das plantas, uma vez que 'Terrinha' e 'D'Angola' apresentaram menor porte que 'Terra Maranhão'.

$\mathrm{O}$ número médio de dias decorridos do plantio à floração foi influenciado pela cultivar (Tabela 2). O maior valor foi observado para 'Terra Maranhão' (378 dias), seguida por 'Terrinha' (321 dias) e 'D'Angola' (295 dias). Os valores de dias do plantio à floração foram inferiores aos encontrados por Faria et al. (2010), com maior diferença para 'Terra Maranhão' (450 dias) e 'D'Angola' (330 dias). Isso se deve às diferentes condições de cultivo e ambientais (semiárido do sudoeste baiano e subúmido de tabuleiros costeiros).

Com a análise de variância, detectou-se efeito da interação lâmina $x$ cultivar para altura de planta, diâmetro de caule e área foliar, com desdobramento significativo da lâmina apenas para 'Terra Maranhão', o que confirma a maior sensibilidade desta cultivar em relação às demais. A altura da planta, o diâmetro do pseudocaule e a área foliar apresentaram aumento de acordo com uma função polinomial de grau 2, com máximos estimados de 4,37 $\mathrm{m}$ (Figura $2 \mathrm{~A}$ ), 0,33 $\mathrm{m}$ (Figura $2 \mathrm{~B}$ ) e 14,41 $\mathrm{m}^{2}$ (Figura 2 C), respectivamente. Esses valores corresponderam às lâminas de água aplicadas: $1.404 \mathrm{~mm}$ para altura da planta, $1.416 \mathrm{~mm}$ para diâmetro do pseudocaule e $1.375 \mathrm{~mm}$ para área foliar.

O número de dias do plantio à floração não sofreu influência significativa das lâminas aplicadas, entretanto, foi reduzido em 10, 30 e 20 dias, respectivamente, nas três cultivares, à medida que se passou da lâmina de $33 \%$ da ETc para a de $120 \%$ da ETc.

Em termos de resposta fisiológica das plantas, foram registrados maiores temperatura $\left(30^{\circ} \mathrm{C}\right)$, radiação global (2,17 MJ m² por hora) e deficit de pressão de vapor d'água $(1,89 \mathrm{kPa})$, bem como menor umidade relativa do ar (50\%), na segunda avaliação. Os efeitos dos tratamentos ficaram sujeitos às condições micrometeorológicas, associados à existência de água disponível na zona efetiva do sistema radicular.
Houve efeito significativo do desdobramento do fator lâmina de irrigação dentro de cada cultivar, na
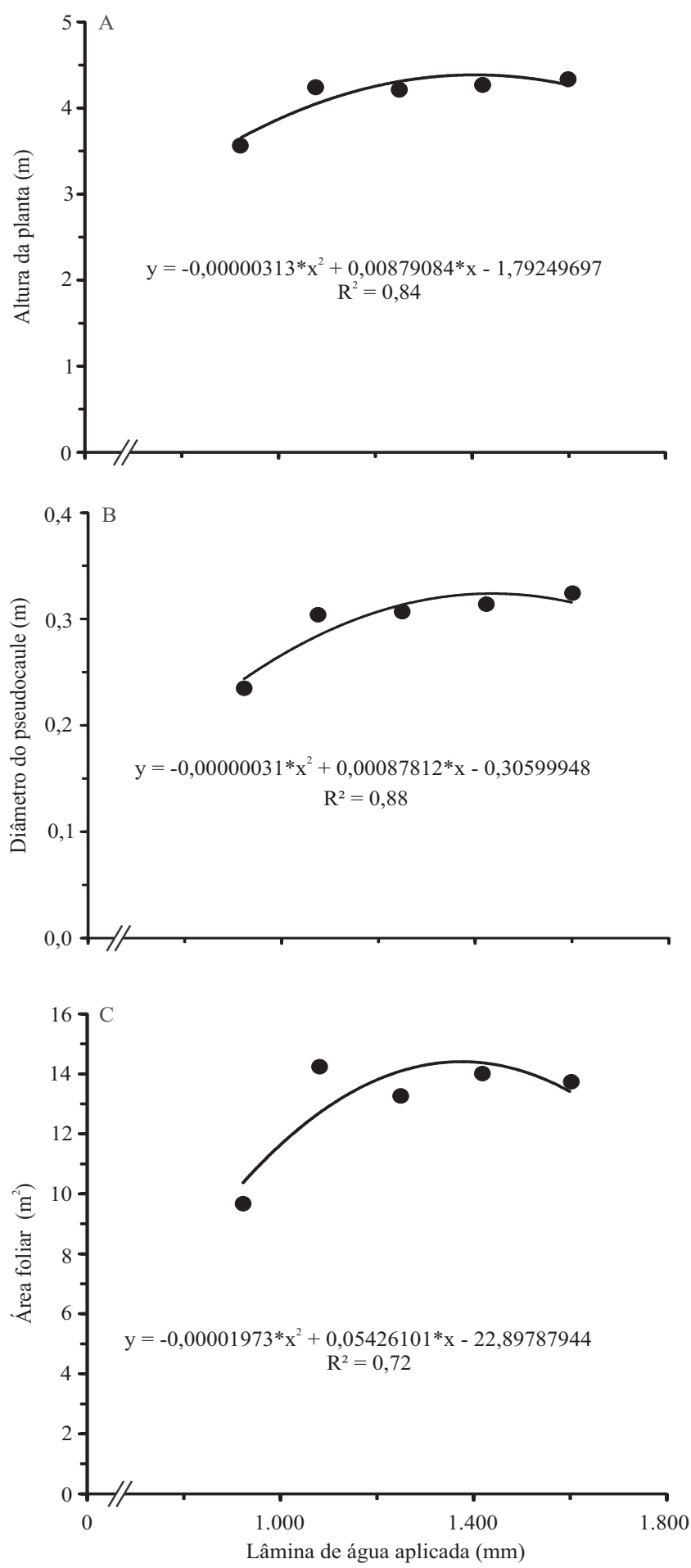

Figura 2. Variáveis de crescimento: altura da planta (A), diâmetro do pseudocaule (B) e área foliar (C), em função da lâmina de água aplicada.

Pesq. agropec. bras., Brasília, v.48, n.9, p.1260-1268, set. 2013 DOI: 10.1590/S0100-204X2013000900010 
condutância estomática (Tabela 3). Nas parcelas em sequeiro $(0 \%$ da ETc), a condutância estomática foi baixa em todas as cultivares, em razão da produção de ácido abscísico nas folhas, com consequente fechamento dos estômatos (Schroeder et al., 2001), o que evidencia a reação das plantas às condições de deficit hídrico no solo. Com a aplicação das lâminas de irrigação, houve aumento na condutância das cultivares, em que 'D'Angola' passou a responder linearmente ao acréscimo de água aplicada, enquanto 'Terrinha' manteve menor sensibilidade aos incrementos da lâmina de irrigação, o que pode ser verificado pelos ajustes de modelos polinomiais de segunda ordem aos dados (Figura 3 A e B), na segunda avaliação. Os valores máximos das condutâncias estomáticas estão em consonância com a aplicação das maiores lâminas de água ao solo.

Com a variação da temperatura de 25 para $30^{\circ} \mathrm{C}$, da umidade relativa de 75 para $50 \%$ e com o aumento da radiação e do deficit de pressão de vapor, a cultivar Terra Maranhão apresentou maior controle estomático, tendo-se observado redução média de $29 \%$ da condutância estomática. As cultivares D’Angola e Terrinha apresentaram aumento da condutância estomática (118 e 18\%, respectivamente), resultante do aumento do gradiente de pressão de vapor, associado à maior luminosidade, o que favoreceu a abertura estomática nessas cultivares. Não houve diferença entre as médias de condutância estomática na primeira avaliação, nas três cultivares, para as lâminas de 33 e 99\% da ETc. Quanto às lâminas de 66 e 120\% da ETc, as médias de condutância estomática para 'Terrinha' e 'D' Angola' foram superiores à da cultivar Terra Maranhão. Na segunda avaliação, as médias de condutância estomática das cultivares diferiram entre si, com maior média para 'D'Angola', seguida por 'Terrinha' e 'Terra Maranhão' (Tabela 3).

Os valores de condutância estomática obtidos na primeira avaliação são próximos dos encontrados por Melo et al. (2009), que avaliaram as características fisiológicas da bananeira 'Prata Anã', nos tabuleiros costeiros do Estado de Sergipe, e relataram valores de condutância estomática na faixa de $344,15 \mathrm{mmol} \mathrm{m}^{-2} \mathrm{~s}^{-1}$, com o solo em sua capacidade de campo $\left(0,199 \mathrm{~m}^{3} \mathrm{~m}^{-3}\right)$.

Terra Maranhão foi a cultivar que apresentou maior regulação da abertura estomática, contrariamente

Tabela 3. Efeito da condutância estomática $\left(\mathrm{mmol} \mathrm{m} \mathrm{m}^{-2} \mathrm{~s}^{-1}\right)$ entre as cultivares dentro de cada lâmina de irrigação $(0,33,66$, 99 e $132 \%$ da evapotranspiração da cultura) aplicada na primeira (I) e na segunda (II) avaliação(1).

\begin{tabular}{|c|c|c|c|c|c|c|c|c|c|c|}
\hline \multirow{2}{*}{ Cultivares } & \multicolumn{2}{|c|}{0} & \multicolumn{2}{|c|}{33} & \multicolumn{2}{|c|}{66} & \multicolumn{2}{|c|}{99} & \multicolumn{2}{|c|}{132} \\
\hline & I & II & I & II & I & II & I & II & I & II \\
\hline D'Angola & $54,6 \mathrm{a}$ & $156,6 \mathrm{a}$ & $177,0 \mathrm{a}$ & $230,0 \mathrm{ab}$ & $236,0 \mathrm{ab}$ & $480,0 \mathrm{a}$ & $312,6 a$ & $653,3 a$ & $406,6 a$ & $1.073,0 \mathrm{a}$ \\
\hline Terrinha & $20,5 \mathrm{a}$ & $30,0 \mathrm{~b}$ & $166,6 \mathrm{a}$ & $316,6 \mathrm{a}$ & $333,3 \mathrm{a}$ & $260,0 \mathrm{~b}$ & $240,0 \mathrm{a}$ & $266,6 b$ & $546,6 a$ & $373,3 b$ \\
\hline Terra Maranhão & $15,8 \mathrm{a}$ & $4,0 \mathrm{~b}$ & $172,3 \mathrm{a}$ & $166,6 b$ & $149,3 \mathrm{~b}$ & $193,3 b$ & $350,0 \mathrm{a}$ & $133,3 \mathrm{c}$ & $340,3 b$ & $306,6 \mathrm{~b}$ \\
\hline
\end{tabular}

${ }^{(1)}$ Médias seguidas de letras iguais, minúsculas nas colunas, não diferem pelo teste de Tukey, a 5\% de probabilidade. Diferença mínima significativa a 5\% de probabilidade pelo teste de Tukey (DMS) na avaliação I = 117,49; DMS na avaliação II = 122,30.
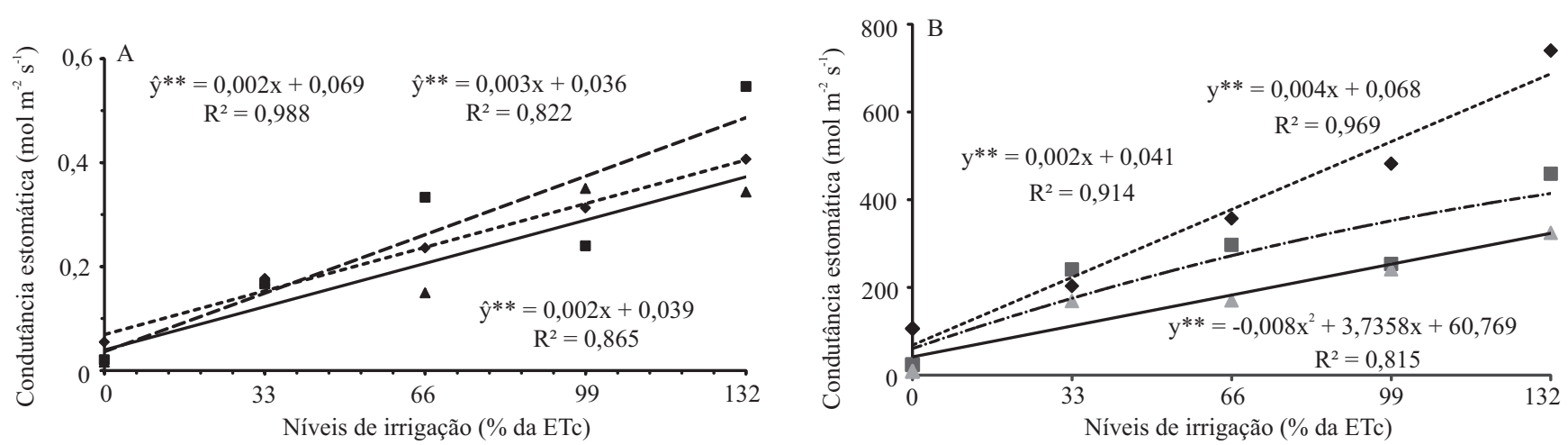

$$
\bullet \text { D'Angola } \boldsymbol{\square} \text { Terrinha } \Delta \text { Terra Maranhão }
$$

Figura 3. Condutância estomática, na fase vegetativa, em três cultivares da bananeira tipo Terra antes de nova irrigação, em função de níveis de irrigação. A, primeira avaliação; e B, segunda avaliação. 
ao comportamento de 'D'Angola' diante da elevação dos níveis de água no solo. Isso decorre da variação fisiológica entre as cultivares, pois algumas apresentam maior capacidade de economizar água do que outras. Deve-se ressaltar que os estômatos das folhas das bananeiras respondem sensivelmente à aridez do ar e ao secamento do solo, e as cultivares, de maneira diferente às características ambientais (Turner et al., 2007). Semelhantemente ao observado no presente trabalho, para a cultivar D'Angola, Cayón et al. (2000) verificou, em condições controladas, para o plátano 'Dominco-Harton', condutância estomática inversa à condição da umidade do ar.

No presente trabalho, os valores de condutância estomática obtidos foram, em geral, maiores para as menores umidades relativas do ar e os maiores deficits de pressão de vapor, tendo sido superiores aos relatados por Cayón et al. (2000), que considerou altos os valores de condutância estomática de $0,2 \mathrm{~mol} \mathrm{~m}^{-2} \mathrm{~s}^{-1}$, em umidade relativa de 53 a $61 \%$, e baixos, os de condutância estomática de $0,1 \mathrm{~mol} \mathrm{~m}^{-2} \mathrm{~s}^{-1}$, em umidade relativa acima de $65 \%$. O comportamento da condutância estomática em relação ao deficit de pressão de vapor também diferiu do observado por Passos et al. (2005) e Costa \& Marenco (2007), cujos dados indicaram redução de condutância estomática com o aumento do deficit de pressão de vapor.

Constatou-se efeito significativo para o fator cultivar, em todas as variáveis de produção avaliadas (Tabela 4). A cultivar D'Angola apresentou os menores valores, tendo-se caracterizado como de ciclo mais curto, porém de mais baixa produtividade. Já a cultivar Terrinha apresentou produtividade significativamente superior à de 'D' Angola' e ciclo maior que o desta cultivar, porém inferior ao de 'Terra Maranhão'. A cultivar Terra Maranhão, mesmo com um ciclo mais longo, apresentou os melhores resultados de produção,

Tabela 4. Médias de número de dedos, número de pencas, peso de pencas e dias do ciclo (DAC), referentes às três cultivares avaliadas ${ }^{(1)}$.

\begin{tabular}{lcccc}
\hline Cultivares & $\begin{array}{c}\text { Número de } \\
\text { dedos }\end{array}$ & $\begin{array}{c}\text { Número de } \\
\text { pencas }\end{array}$ & $\begin{array}{c}\text { Peso de pencas } \\
\left(\mathrm{Mg} \mathrm{ha}^{-1}\right)\end{array}$ & DAC \\
\hline D’Angola & $34,47 \mathrm{c}$ & $6,36 \mathrm{~b}$ & $11,9 \mathrm{c}$ & $384 \mathrm{c}$ \\
Terrinha & $87,59 \mathrm{~b}$ & $6,85 \mathrm{~b}$ & $17,0 \mathrm{~b}$ & $407 \mathrm{~b}$ \\
Terra Maranhão & $150,53 \mathrm{a}$ & $9,55 \mathrm{a}$ & $27,0 \mathrm{a}$ & $466 \mathrm{a}$ \\
\hline
\end{tabular}

${ }^{(1)}$ Médias seguidas de letras iguais, minúsculas nas colunas, não diferem pelo teste de Tukey, a 5\% de probabilidade. tendo superado as outras cultivares em todas as variáveis de produção analisadas, conforme esperado, em razão da sua própria constituição morfológica, com crescimento maior do que o das demais.

As médias de número de pencas por cacho foram inferiores às obtidas por Faria et al. (2010), que relataram valores de 11,8 e 7 pencas por cacho, para as cultivares Terra Maranhão, Terrinha e D'Angola, respectivamente; porém, foram próximas das médias encontradas por Silva et al. (2008), para as cultivares Terra Maranhão (dez pencas) e D'Angola (sete pencas). As médias de número de dedos por cacho também foram inferiores às relatadas por Faria et al. (2010) nas três cultivares: 186 em Terra Maranhão, 93 em Terrinha e 36 em D'Angola, bem como por Silva et al. (2008) em 'D'Angola'. As médias de peso de pencas por cacho das cultivares Terrinha e D'Angola foram próximas às obtidas por Faria et al. (2010), o que não ocorreu para 'Terra Maranhão', uma vez que o peso de pencas médio registrado pelos autores foi maior que o obtido no presente trabalho.

As lâminas de irrigação tiveram efeito significativo em algumas das variáveis de produção analisadas. Verificou-se elevação linear da produtividade em relação às lâminas (Figura $4 \mathrm{~A}$ ). $\mathrm{O}$ número de pencas por cacho e de dedos por pencas (Figuras $4 \mathrm{~B}$ e $4 \mathrm{C}$ ) apresentaram relação quadrática com a lâmina de uso consuntivo. O máximo estimado de número de pencas por cacho foi observado com uso da lâmina de $1.478 \mathrm{~mm}$ (1,04 da ETc), e o de dedos por pencas, com a lâmina de $1.424 \mathrm{~mm}(1,00 \mathrm{da} \mathrm{ETc})$. A produtividade máxima física estimada ocorreu com a lâmina de $1.599 \mathrm{~mm}$ (1,20 da ETc). Embora essa produtividade corresponda a uma menor eficiência de uso de água (Figura 4 D), a lâmina de $1.599 \mathrm{~mm}$ é a mais recomendada, já que as duas menores lâminas acarretaram reduções de pelo menos $12,6 \mathrm{Mg} \mathrm{ha}^{-1}$ na produtividade.

No caso de 'Terrinha', que sucedeu a cultivar Terra Maranhão em produtividade (Tabela 4), apenas essa variável apresentou relação quadrática com as lâminas aplicadas (Figura 5). O valor máximo estimado da produtividade física ocorreu com a lâmina de $1.191 \mathrm{~mm}$ (1,08 da ETc), o que também correspondeu à mais baixa eficiência de uso de água $\left(32,69 \mathrm{~kg} \mathrm{~mm}^{-1}\right)$. Nesse caso, a redução da lâmina para $922 \mathrm{~mm}(0,84 \mathrm{da} \mathrm{ETc})$ elevou a eficiência de uso de água para $37,4 \mathrm{~kg} \mathrm{~mm}^{-1}$, com redução na 
produtividade de apenas $1,1 \mathrm{Mg} \mathrm{ha}^{-1}$. A cultivar Terrinha apresentou valores de produtividade e variáveis de crescimento, exceto diâmetro de caule, superiores aos de 'D'Angola' (Tabela 4). A produtividade de 'D’Angola' apresentou relação quadrática com as lâminas de água, com máximo estimado para a lâmina
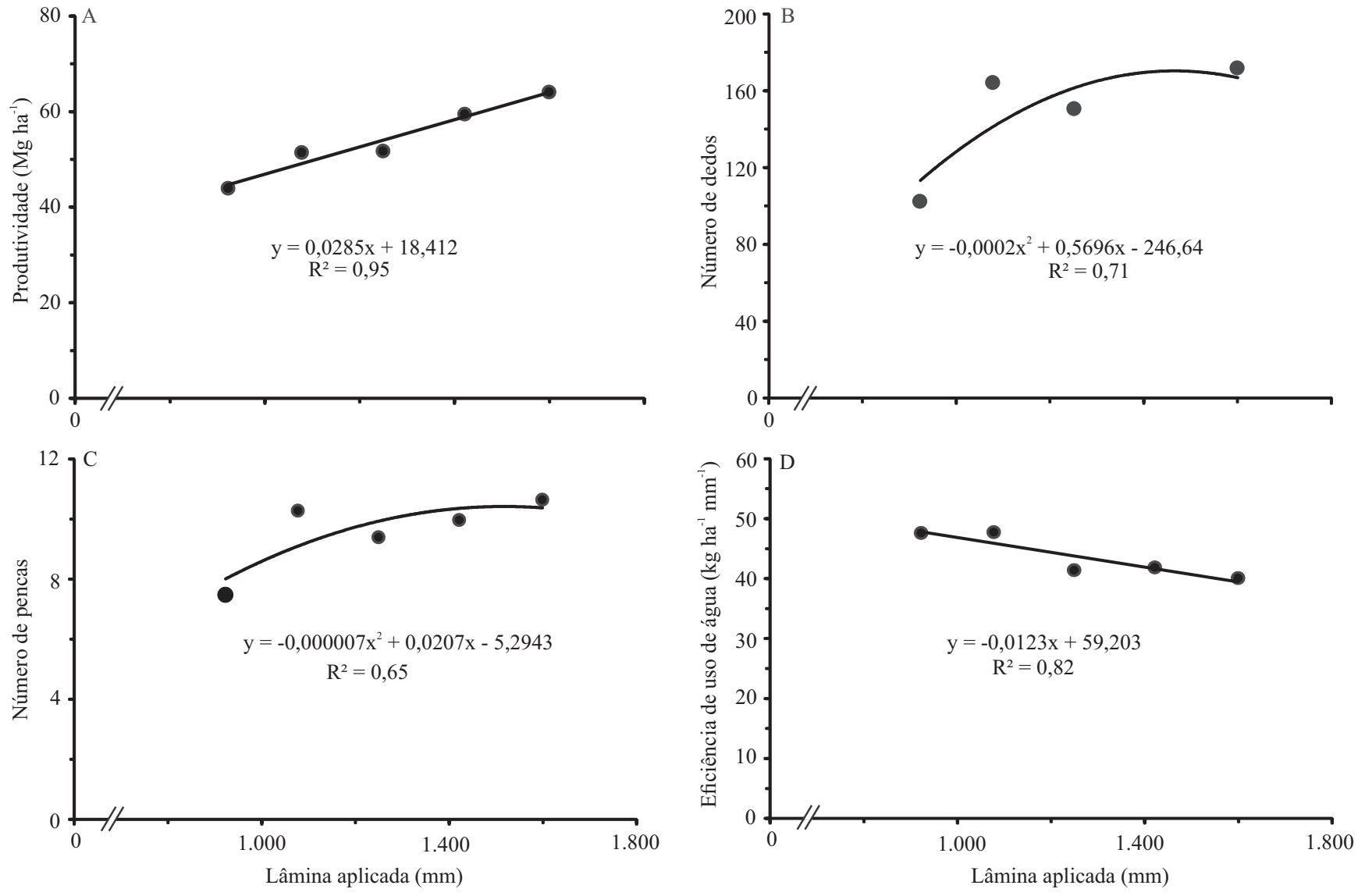

Figura 4. Produtividade de pencas (A), número de pencas (B), número de dedos (C) e eficiência de uso de água (D) da cultivar Terra Maranhão, em função da lâmina de água aplicada.
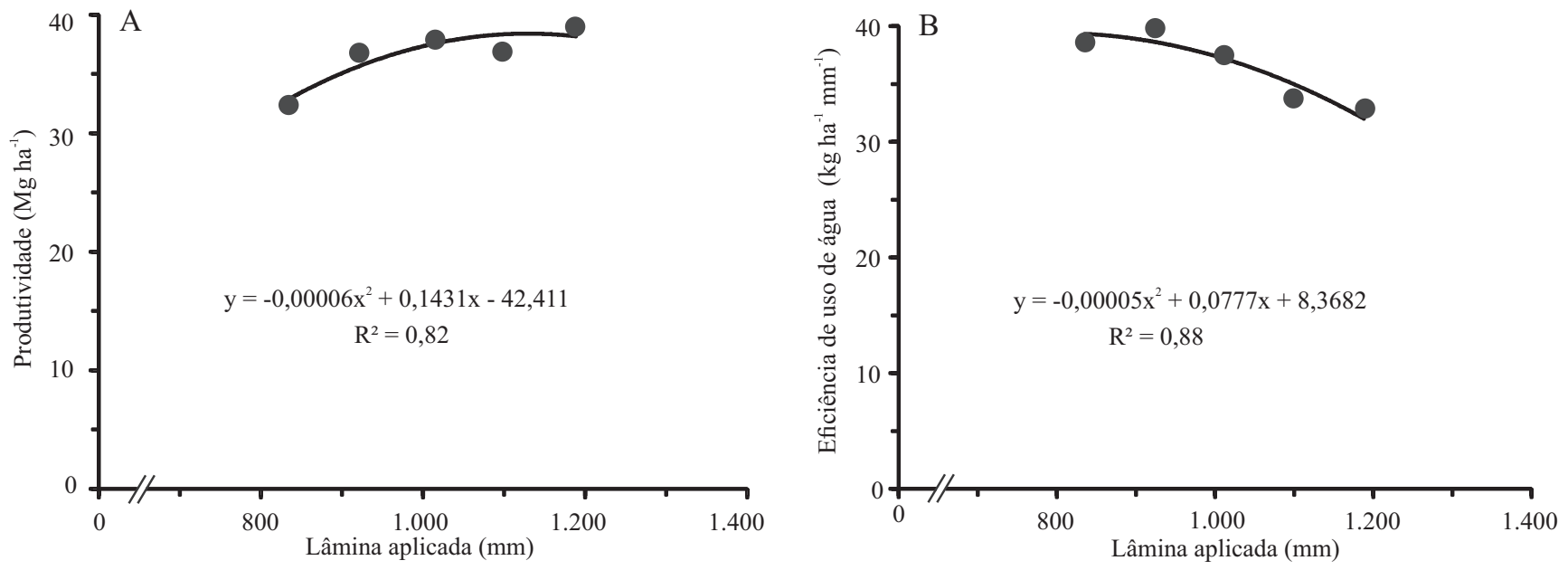

Figura 5. Produtividade (A) e eficiência de uso de água (B) da cultivar Terrinha, no primeiro ciclo, em função da lâmina de água aplicada. 
de $940 \mathrm{~mm}$ (Figura 6). Esse valor correspondeu ao máximo de eficiência de uso de água, em que a lâmina de $940 \mathrm{~mm}$ (1,06 da ETc) foi considerada a mais adequada para a cultivar D'Angola (Figura 6 B).

$\mathrm{O}$ aumento linear ou quadrático da produtividade, com o aumento da lâmina de uso consuntivo, também foi observado em outros trabalhos com cultivares de bananeiras (Coelho et al., 2006; Figueiredo et al., 2006). Os resultados também são próximos dos encontrados por Goenaga et al. (1995), que obtiveram maiores produtividades de plátanos com lâminas iguais ou maiores que $75 \%$ da evaporação do tanque classe A, ou seja, valores próximos ou superiores aos da evapotranspiração da cultura. As cultivares diferiram quanto às necessidades hídricas durante o ciclo, o que pode ser constatado pelos coeficientes de cultura (Figura 7), com maiores taxas de variação para a cultivar Terra Maranhão, seguida por 'D'Angola' e 'Terrinha', que apresentaram valores próximos entre si, o que é indicativo da maior e da menor
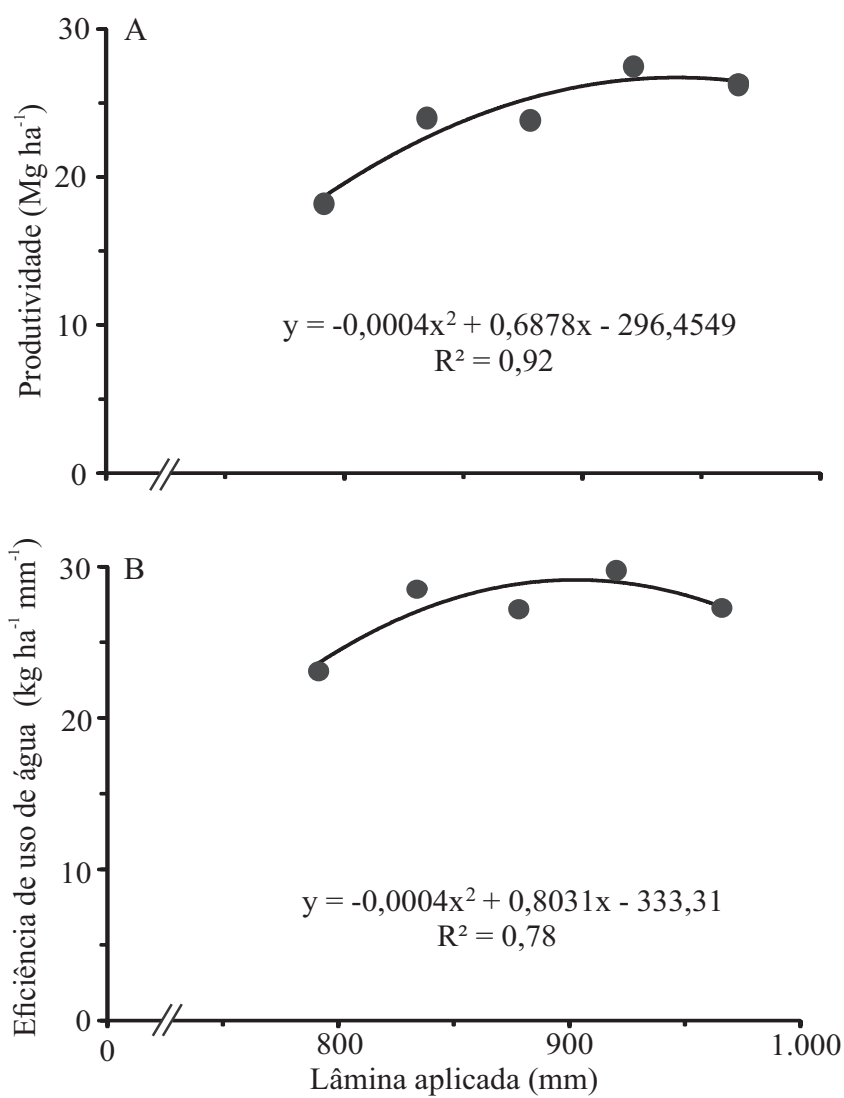

Figura 6. Produtividade (A) e eficiência de uso de água (B) da cultivar D'Angola, no primeiro ciclo, em função da lâmina de água aplicada.

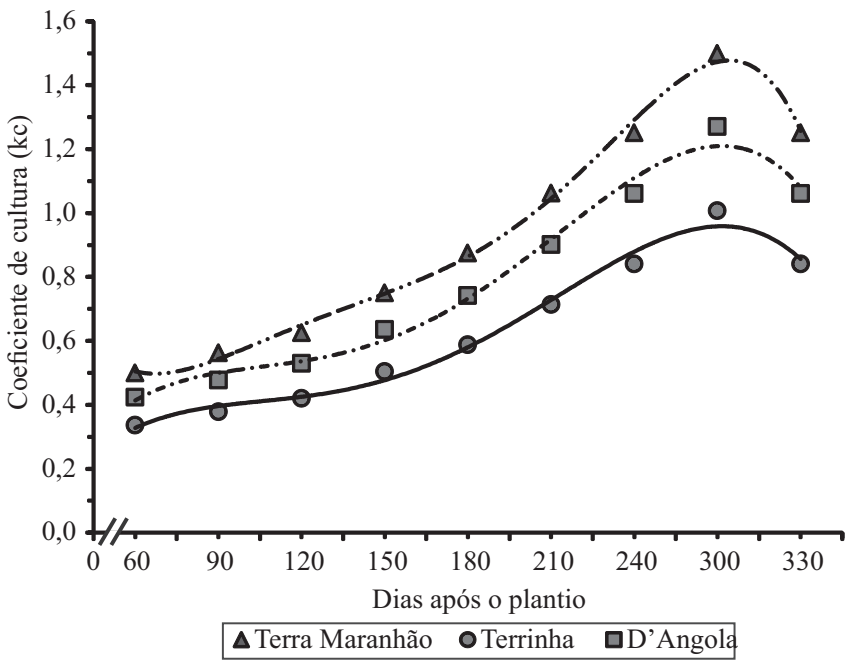

Figura 7. Coeficientes de cultura para as cultivares Terra Maranhão, Terrinha e D'Angola, no primeiro ciclo da cultura, em função do número de dias após o plantio.

necessidade hídrica das cultivares Terra Maranhão e Terrinha, respectivamente. Esses resultados não estão de acordo com os obtidos por Albruna et al. (1980), em Vertissolos de Porto Rico, cujos valores da evapotranspiração de plátanos ficaram entre 60 e $80 \%$ da evaporação do tanque classe A nas fases de crescimento vegetativo e produtivo, respectivamente. Deve-se, portanto, considerar que os coeficientes de cultura referem-se às condições climáticas do recôncavo da Bahia, especificamente, de Cruz das Almas, com predominância de Latossolo Amarelo.

\section{Conclusões}

1. A cultivar Terra Maranhão é superior às cultivares D'Angola e Terrinha em altura, diâmetro de caule e área foliar.

2. A cultivar Terra Maranhão apresenta maior capacidade de regulação estomática com a elevação dos níveis de água no solo do que as cultivares Terrinha e D'Angola.

3. As produtividades associadas às eficiências de uso de água mais adequadas para as cultivares Terra Maranhão, Terrinha e D'Angola são obtidas com a aplicação das lâminas de água de $1.599 \mathrm{~mm}(1,20 \mathrm{da}$ ETc), 922 mm (0,84 da ETc) e 940 mm (1,06 da ETc), respectivamente.

Pesq. agropec. bras., Brasília, v.48, n.9, p.1260-1268, set. 2013 DOI: 10.1590/S0100-204X2013000900010 


\section{Referências}

ALBRUNA, F.; VICENTE CHANDLER, J.; IRIZARRY, H.; SILVA, S. Evapotranspiration with plantains and the effect of frequency of irrigation on yields. Journal of Agriculture of the University of Puerto Rico, v.64, p.204-210, 1980.

ARANTES, A. de M.; DONATO, S.L.R.; SILVA, S. de O. e. Relação entre características morfológicas e componentes de produção em plátanos. Pesquisa Agropecuária Brasileira, v.45, p.224-227, 2010. DOI: 10.1590/S0100-204X2010000200015.

BORGES, A.L.; SILVA, T.O. da; CALDAS, R.C.; ALMEIDA, I.E. de. Adubação nitrogenada para bananeira-'Terra' (Musa sp. AAB, subgrupo Terra). Revista Brasileira de Fruticultura, v.24, p.189-193, 2002. DOI: 10.1590/S0100-29452002000100041.

BRAGA FILHO, J.R.; NASCIMENTO, J.L. do; NAVES, R.V.; SILVA, L.B. e; PEREIRA, A.C. da C.P.; GONÇALVES, H.M.; RODRIGUES, C. Crescimento e desenvolvimento de cultivares de bananeira irrigadas. Revista Brasileira de Fruticultura, v.30, p.981-988, 2008. DOI: 10.1590/S0100-29452008000400024.

CAYÓN, G. Ecofisiología y productividad del plátano (Musa AAB Simmonds). In: REUNIÓN DE LA ASOCIACIÓN PARA LA COOPERACIÓN EN INVESTIGACIÓN DE BANANO EN 294 EL CARIBE Y EN AMERICA TROPICAL, 16., 2004, Oaxaca. Anais. Oaxaca: Acorbat, 2004. p.172-183.

CAYÓN, G.; MORALES, H.; CELIS, L.D. Respuestas del plátano Dominico-Harton (Musa AAB Simmonds) a la defoliación selectiva en la zona cafetera central. Acta Agronómica, v.50, p.20-25, 2000.

COELHO, E.F.; DONATO, S.L.R.; OLIVEIRA, P.M. de; CRUZ, A.J.S. Relações hídricas II: evapotranspiração e coeficiente de cultura. In: COELHO, E.F. (Ed.). Irrigação da bananeira. Brasília: Embrapa, 2012. p.87-117.

COELHO, E.F.; LEDO, C.A. da S.; SILVA, S. de O. Produtividade da bananeira 'Prata-anã' e 'Grande Naine' no terceiro ciclo sob irrigação por microaspersão em tabuleiros costeiros da Bahia. Revista Brasileira de Fruticultura, v.28, p.435-438, 2006. DOI: 10.1590/S0100-29452006000300021.

COSTA, F. da S.; COELHO, E.F.; BORGES, A.L.; PAMPONET, A.J.M.; SILVA, A. dos A. S.M. da; AZEVEDO, N.F. de. Crescimento, produção e acúmulo de potássio em bananeira 'Galil 18' sob irrigação e fertilização potássica. Pesquisa Agropecuária Brasileira, v.47, p.409-416, 2012. DOI: 10.1590/ S0100-204X2012000300013.

COSTA, G.F. da; MARENCO, R.A. Fotossíntese, condutância estomática e potencial hídrico foliar em árvores jovens de andiroba (Carapa guianensis). Acta Amazonica, v.37, p.229-234, 2007. DOI: $10.1590 /$ S0044-59672007000200008.
FARIA, H.C. de; DONATO, S.L.R.; PEREIRA, M.C.T.; SILVA, S. de O. e. Avaliação fitotecnica de bananeiras tipo Terra sob irrigação em condições semi-áridas. Ciência e Agrotecnologia, v.34, p.830-836, 2010. DOI: 10.1590/S1413-70542010000400006.

FIGUEIREDO, F.P. de; MANTOVANI, E.; SOARES, A.A.; COSTA, L.C.; RAMOS, M.M.; OLIVEIRA, F.G. Produtividade e qualidade da banana 'Prata-Anã', influenciada por lâminas de água, cultivada no Norte de Minas Gerais. Revista Brasileira Engenharia Agrícola e Ambiental, v.10, p. 798-803, 2006. DOI: 10.1590/S1415-43662006000400003.

GOENAGA, R.; IRIZARRY, H.; COLEMAN, B.; ORTIZ, E. Drip irrigation recommendations for plantain and banana grown on the semiarid southern coast of Porto Rico. The Journal of Agriculture of the University of Porto Rico, v.79, p.13-27, 1995.

MELO, A.S. de; SILVA JUNIOR, C.D. da; FERNANDES, P.D.; SOBRAL, L.F.; BRITO, M.E.B.; DANTA, J.D.M. Alterações das características fisiológicas da bananeira sob condições de fertirrigação. Ciência Rural, v.39, p.733-741, 2009. DOI: 10.1590/ S0103-84782008005000101.

PASSOS, C.D.; PASSOS, E.E.M.; PRADO, C.H.B. de A. Comportamento sazonal do potencial hídrico e das trocas gasosas de quatro variedades de coqueiro-anão. Revista Brasileira de Fruticultura, v.27, p.248-254, 2005. DOI: 10.1590/ S0100-29452005000200016.

SCHROEDER, J.I.; ALLEN, G.J.; HUGOUVIEUX, V.; KWAK, J.M.; WANER, D. Guard cell signal transduction. Annual Review of Plant Physiology and Plant Molecular Biology, v.52, p.627-658, 2001. DOI: 10.1146/annurev.arplant.52.1.627.

SILVA, S. de O. e; PEREIRA, L.V.; RODRIGUES, M.G.V. Bananicultura irrigada: inovações tecnológicas. Variedades. Informe Agropecuário, v.29, p.78-83, 2008.

SOTO, M. Situación y avances tecnologicos en la producción bananera mundial. Revista Brasileira de Fruticultura, v.33, p.013-028, 2011. DOI: /10.1590/S0100-29452011000500004.

SOUZA, L. da S.; SOUZA, L.D. Caracterização físico-hídrica de solos da área do Centro Nacional de Pesquisa de Mandioca e Fruticultura Tropical. Cruz das Almas: Embrapa Mandioca e Fruticultura, 2001. 56p. (Embrapa Mandioca e Fruticultura. Boletim de pesquisa e desenvolvimento, 20).

TURNER, D.W.; FORTESCUE, J.A.; THOMAS, D.S. Environmental physiology of the bananas (Musa spp.). Brazilian Journal of Plant Physiology, v.19, p.463-484, 2007. DOI: 10.1590/S1677-04202007000400013.

ZUCOlOTO, M.; LIMA, J.S. de S.; COELHO, R.I. Modelo matemático para estimativa da área foliar total de bananeira 'Prata-Anã'. Revista Brasileira de Fruticultura, v.30, p.1152-1154, 2008. DOI: 10.1590/S0100-29452008000400050.

Recebido em 10 de abril de 2013 e aprovado em 18 de agosto de 2013 